\title{
La maja maldita: retrato tardío de una femme fatale
}

\author{
Carlos Primo Cano \\ Universidad Complutense de Madrid
}

Título: La maja maldita: retrato tardío de una femme fatale.

Resumen: Este artículo analiza la pintura La maja maldita (1918) de Federico Beltrán Massés y la vincula al soneto que le dedicó el poeta Armand Godoy en 1926. El análisis da cabida al contexto sociocultural de ambas obras y a la recepción crítica y popular de uno de los artistas más significativos del art déco español.

Palabras clave: Decadentismo, Federico Beltrán Massés, Écfrasis, Art déco en España, Armand Godoy.

Fecha de recepción: 30/7/2015.

Fecha de aceptación: 18/8/2015.
Title: La maja maldita: Late Portrait of a Femme Fatale.

Abstract: This article analyses La maja maldita (1918), a painting by Federico Beltrán Massés, and relates the pictorial work to a sonnet that Armand Godoy wrote under its inspiration. The study reflects the social and cultural context of both works, and researches into the critical reception of one of Spanish art déco's most prominent artists.

Key words: Decadentism, Federico Beltrán Massés, Armand Godoy, Ekphrasis, Art déco in Spain.

Date of Receipt: 30/7/2015.

Date of Approval: 18/8/2015.

Las relaciones entre literatura y artes plásticas no son patrimonio exclusivo de una escuela, un periodo o un estilo. En todas las épocas ha habido, en distintos ámbitos y con distintas implicaciones, vínculos temáticos y estéticos entre escritores y artistas visuales cuyos resultados dan cabida a manifestaciones tan diversas como la ilustración de relatos literarios, la 
descripción literaria de obras plásticas o la écfrasis, acaso el género que mejor ilustra el grado de intensidad que puede alcanzar esta relación. Sin embargo, resulta innegable que hay épocas y estilos literarios más plásticos que otros y, en ese sentido, a nadie se le escapa que las relaciones entre literatura y artes plásticas vivieron a finales del siglo XIX y principios del $\mathrm{XX}$ un auge sólo comparable al experimentado en periodos tan radiantes como el Barroco secentista.

En el Modernismo, influencias tan dispares como la sensibilidad estética tardorromántica, la obra total wagneriana o la teoría de las correspondencias enunciada por Baudelaire dieron lugar a un considerable corpus textual que hoy sigue proporcionando abundante material para el estudio. Los autores del Modernismo dirigieron su atención a obras plásticas de todo tipo: paisajes, pinturas de tema histórico o legendario, naturalezas muertas, escenas de costumbres y, también, retratos. Este último género pictórico ofrece un interés adicional, ya que las posibilidades de análisis se multiplican, y a los dos términos de la comparación -la obra pictórica y la obra literaria- hay que ańadir un tercero: la personalidad del retratado y sus implicaciones sociales, históricas e interartísticas. En ese sentido, el estudio comparado del tema de La maja maldita en la obra del pintor Federico Beltrán Massés y del poeta Armand Godoy ofrece posibilidades que van más allá del análisis de sus obras respectivas, y proporciona el punto de partida para establecer una red de referencias, nombres y acontecimientos que permiten contemplar, al menos de manera fugaz, una época concreta y poco conocida de la España contemporánea.

\section{El casticismo aRT déCo de Federico Beltrán Massés}

En ese sentido, el retrato español de las décadas de 1910 y 1920 presenta un atractivo innegable ${ }^{1}$. De forma paralela al surgimiento, consolidación y transformación de las Vanguardias, la sensibilidad modernista se prolongaría en las artes plásticas españolas hasta el inicio de la guerra. En

1 En los últimos años, la puesta en valor de artistas y movimientos artísticos de inicios del siglo XX en España ha propiciado la aparición de exposiciones y estudios como El retrato moderno en España (1906-1936). Itinerarios y procesos, Madrid, Fundación Santander / Real Academia de Bellas Artes de San Fernando, 2007. 
España, el fin de siècle duraría hasta bien entrado el siglo XX y, de ese modo, las estribaciones del Simbolismo -Romero de Torres, Anglada Camarasa- desembocarían en una versión española del art déco que, aunque no excesivamente conocida para el público actual, sí gozó de una considerable popularidad entre los espectadores y coleccionistas de la época ${ }^{2}$. Esta celebridad y aceptación se debió tanto a la inmediatez de su lenguaje plástico como a los temas explorados por esta nueva corriente estética, entre los que se encontraba el retrato de celebridades de aquella España que el novelista Antonio de Hoyos y Vinent definiría como afectada por la "maravillosa decadencia que precedió a la guerra"3.

Aristócratas, artistas, intelectuales y celebridades de salón quisieron ser inmortalizados, y para ello acudieron a pintores capaces de expresar -y volvemos a Hoyos- aquella "enfermiza sensibilidad que, poniendo impresionabilidad extraña en nuestras retinas, teñía de color las horas"4. Entre los pintores del art déco español, el más célebre fue Federico Beltrán Massés (1885-1949). Resulta llamativo que este artista, que en las primeras décadas del siglo XX estuvo considerado como uno de los más célebres y prósperos pintores hispanos, cayera durante décadas en un silencio casi completo por parte de los ámbitos crítico y expositivo.

$\mathrm{Al}$ igual que ha sucedido con otros representantes de las estéticas finiseculares en la pintura española-Beltrán Massés nació en Cuba, pero su formación y su cultura son plenamente españolas y, en todo caso, están impregnadas del cosmopolitismo tan característico de aquella época-, su obra no ha sido recuperada más que en fechas muy recientes. 5 . De este

2 El estudio más extenso y exhaustivo sobre la evolución del art déco en España es la imprescindible monografía de Francisco Javier Pérez Rojas, El art déco en España, Madrid, Cátedra, 1990.

3 Antonio de Hoyos y Vinent, "La hora violeta", en Prodigiosos mirmidones, eds. Leticia García y Carlos Primo, Madrid, Capitán Swing Libros, 2012, pp. 277-282 (p. 279).

4 Antonio de Hoyos y Vinent, op. cit., p. 279.

5 Apenas encontramos referencias a Federico Beltrán Massés con anterioridad a 1990, cuando Javier Pérez Rojas le dedicó algunas páginas en El art déco en España, op. cit. Casi una década después, Lola Caparrós Masegosa le dedicaba un capítulo en su imprescindible ensayo sobre la pintura española finisecular: Prerrafaelismo, Simbolismo y Decadentismo en la pintura española de Fin de Siglo, Granada, Universidad de Granada, 1999, pp. 230-242. En la actualidad disponemos de dos buenos catálogos dedicados a su obra. El primero es VV.AA., Federico Beltrán Massés, Fundación Manuel Ramos 
modo, el público ha tenido acceso a la fuerza visual y temática que presentan las obras del que fuera un pintor cuyo estilo puede enmarcarse estilísticamente entre el Simbolismo, el Modernismo y el art déco y cuya mayor virtud probablemente sea un exquisito manejo del colorido. Por otro lado, y en sintonía con las corrientes temáticas asociadas a estos movimientos plásticos, la mayor parte de su obra está protagonizada por figuras femeninas, procedentes tanto de la alta sociedad, en forma de retratos, como de la propia imaginación del pintor, que fusionó de manera acertada y evocadora un cierto estilo alegórico con temáticas procedentes del simbolismo y el orientalismo, frecuentemente respaldados por fuentes históricas o legendarias.

Una de sus obras más notorias y llamativas es, sin duda, la pintura $L a$ maja maldita, pintada en 1918 y expuesta en París un año después. Antes de proceder a su análisis, sin embargo, consideramos necesario prestar atención a ciertos antecedentes que permiten comprender de forma global la reacción que el público de la época tuvo ante una obra considerada polémica y abiertamente erótica; adjetivos, en cualquier caso, frecuentemente aplicados a la pintura de Beltrán Massés.

\section{La GÉNesis del escándalo: las majas de Beltrán Massés}

Cuando Federico Beltrán Massés presentó, en 1919, La maja maldita, una seductora pintura ejecutada un año antes, no cabe duda de que el público de la época vio en ella una referencia a uno de los episodios más sonados de la carrera de este singular artista. Su presentación al público tuvo lugar en el marco de la primera exposición del español en Francia, celebrada en el Petit Palais parisino, y no en España, el país donde se

Andrade, Salamanca, 2007, y se publicó con motivo de una exposición estrenada en el Museo Art Nouveau y Art Déco Casa Lis de Salamanca. El segundo, que incluye un notable conjunto de ensayos y abundante documentación visual y hemerográfica, es la fuente más completa y actualizada de la que disponemos: Federico Beltrán Massés. Castizo cosmopolita, ed. Joan Abelló, Madrid/Barcelona, Real Academia de Bellas Artes de San Fernando/Reial Cercle Artístic de Barcelona, 2012. La elaboración de un catálogo razonado de su obra es aún una tarea pendiente que está acometiendo la estudiosa María Antonia Salom de Tord, responsable asimismo del legado del pintor. 
había formado, donde había residido hasta entonces y donde había estallado, en 1915, una de las más vivas polémicas artísticas de aquellos años. Dicha polémica -calificada como escándalo por algunos- se produjo a raíz de la presentación, para su inclusión en la Exposición Nacional de Bellas Artes de 1915, de un cuadro titulado La maja marquesa [Fig. 1].

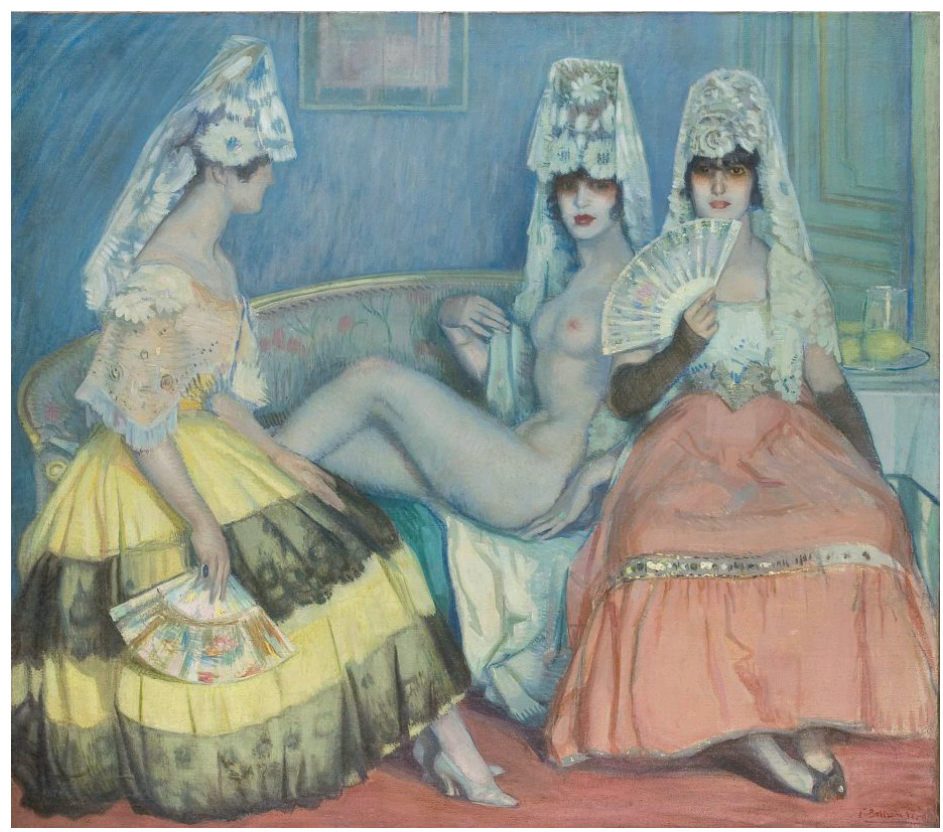

Fig. 1.

La obra, que mostraba a tres mujeres en actitud relajada, una de ellas totalmente desnuda a excepción de una mantilla y una peineta que justificaban tan castizo título, fue rechazada por el jurado basándose en uno de los principios del reglamento, que justificaba la exclusión de pinturas de carácter "repugnante y ofensivo a la moral". Algunos vieron en este gesto un criterio puramente moralista y conservador que rechazaba una representación tan sexualmente ambigua. Sin embargo, la alta sociedad madrileña, de manera casi unánime, consideraba que la inclusión, aparentemente innecesaria, de la palabra "marquesa" en el título constituía una referencia directa a Gloria Laguna, marquesa de La Laguna, una mu- 
jer muy popular en la época a causa de sus poco disimuladas inclinaciones lésbicas $^{6}$. Según esta versión, la pintura habría sido rechazada para evitar la maledicencia.

Sin embargo, como suele ser habitual en este tipo de casos, el acto de censura proporcionó una enorme celebridad a la pintura que se había tratado de silenciar. La decisión del jurado desencadenó una oleada de manifestaciones a favor de la integridad y la valía artística de Federico Beltrán. Varios autores hicieron explícito su apoyo a través de artículos en las principales cabeceras de la época, y llegó a ver la luz un curioso librito, editado por el también artista Gabriel García Maroto, que reunía varios artículos elogiosos hacia Beltrán Massés e incluía además un anexo con varios escritos publicados en prensa a propósito de este asunto ${ }^{7}$. El propio Maroto se refería a Beltrán en términos tan elogiosos y grandilocuentes como los siguientes:

Era muy triste nuestra noche y la luz de La Maja Marquesa alumbró nuestro estrecho sendero. Habíamos perdido el camino de Belén, y el Arte de Beltrán apareció como una estrella guía, como un lucero indicador del camino que conduce a la dicha y a la suprema posesión del Amor y el Arte; ved si hay razón para echar a vuelo las campanas

6 De la popularidad de Gloria Laguna en la sociedad madrileña de la belle époque dan muestra los diversos testimonios y crónicas sociales que la sitúan cerca de artistas y celebridades tan conocidos como Antonio de Hoyos y Vinent y Tórtola Valencia. De hecho, Hoyos y Vinent llegó a inspirarse en ella a la hora de crear el personaje de Paca Campanada, que aparece en varias de sus novelas y que protagoniza pasajes como el siguiente, donde además aparece significativamente descrita como "maja": "Paca Campanada jugaba, fumaba, decía chistes y, contenta de ganar, más por la alegría de la buena suerte que por la ganancia misma, repartía dinero a los que perdían para que siguiesen jugando, con aquella su generosidad llena de airoso desprendimiento, clásica generosidad de maja duquesa que le hacía simpática" (Antonio de Hoyos y Vinent, San Sebastián, coso taurino, Madrid/Buenos Aires, Renacimiento, 1914, pp. 184-185).

7 El volumen, imprescindible para reconstruir la historia de la polémica y conocer sus distintas voces de primera mano, es el siguiente: Federico Beltrán y la Exposición Nacional de Bellas Artes de MCMXV, Madrid, Imprenta Española, 1915. Algunos de los autores incluidos en este libro fueron los siguientes: Gustavo García Maroto, Marceliano Santa María, José Francés, Cecilio Pla, Andrés Bearn de Riquer, J. Romero Lozano, José de Silva, A. Vaquer, Román Jori, Manuel Abril o Rafael Cansinos Assens. 
de nuestro templo, y cortar las rosas y las palmas de nuestro huerto, para ofrecerlas al artista alto de concepto y poderoso de visión que motiva estos comentarios ${ }^{8}$.

Al margen de manifestaciones tan entusiastas como ésta, lo que sí parece claro es que este acontecimiento sirvió para exteriorizar y hacer público un conflicto existente entre la Academia de Bellas Artes y los círculos modernistas, que llevaban tiempo deplorando la exclusión, en las Exposiciones Nacionales de la institución académica, de autores pertenecientes a la órbita simbolista y decadente, como Julio Romero de Torres ${ }^{9}$. Los argumentos a favor de Beltrán relativizaban la identificación con la marquesa de La Laguna y centraban sus esfuerzos en la defensa de los valores artísticos del desnudo y en el elogio de las cualidades plásticas de Beltrán.

A raíz de este suceso, Federico Beltrán Massés alcanzó una enorme popularidad. Tras el rechazo de la obra por parte del jurado de la Nacional, la pintura quedó expuesta al público en un conocido establecimiento dedicado a las bellas artes situado en la madrileña calle del Carmen. Además, se imprimieron miles de tarjetas postales con la reproducción de la obra que incluían, en el reverso, un texto que denunciaba el acto de censura del que había sido objeto.

Si bien es cierto que la repercusión pública de este escándalo no hizo sino aumentar el prestigio de Beltrán entre los círculos modernistas, también hay que resaltar que dicha notoriedad mediática favoreció una discusión pública en torno a los valores plásticos y estéticos de la obra del cubano. Entre 1915 y 1930 varios autores publicaron reflexiones críticas acerca de los cuadros de Beltrán, tanto en forma de libro o catálogo como en críticas y reseñas aparecidas en la prensa periódica española y francesa. Resulta llamativo que, de forma mayoritaria, muchos de estos autores coincidan a la hora de señalar las deudas estilísticas de un pintor

8 Gabriel García Maroto, "Palabras", en Federico Beltrán y la Exposición Nacional de Bellas Artes de MCMXV, Madrid, Imprenta Española, 1915, pp. 8-9.

9 El paso de Julio Romero de Torres por las Exposiciones Nacionales de Bellas Artes estuvo repleto de altibajos que desembocaron en el escándalo de 1906, cuando el jurado rechazó su obra Vividoras del amor por considerarla de naturaleza inmoral. Estos y otros avatares han sido recogidos, entre otros, en la monografía de Francisco Calvo Serraller, Julio Romero de Torres, Madrid, Fundación MAPFRE/Instituto de Cultura, 2006, pp. 28-29. 
estrechamente vinculado con los movimientos finiseculares y asociado, especialmente para el público francés, a los motivos clásicos de la temática españolista que habían popularizado, entre otros, Zuloaga y Romero de Torres. Así lo demuestra la siguiente apreciación del crítico Camille Mauclair:

Mais Beltran a gardé ce même souci de l'expression dans ses figures imaginées. Elles sont nettement espagnoles par le caractère et le galbe, elles sont d'un artiste profondement imbu de l'âme de sa race, et c'est seulement dans cette région que l'œuvre de Beltran semble tangente à celle de son ainé Zuloaga. Ils sont deux célébrateurs de la beauté hispanique ardente, grave, capricieuse, sensuelle, telle que le merveilleux Goya la peignit ${ }^{10}$.

No obstante, no son sólo de origen español las referencias citadas por Mauclair. El crítico también subraya la atmósfera decadente que rodea a las representaciones de esta "beauté hispanique", y sus palabras remiten indudablemente al arquetipo de la femme fatale y, curiosamente, a algunos de sus principales creadores, tanto en el ámbito literario como en el artístico:

Ses beautés aux chevelures de ténèbres, aux teints pâles, aux bouches sanglantes, aux énormes yeux phosphorescents, aux corps musclés et souples de félins humains, apparaissent comme des filles de Bau-

10 "Beltrán ha conservado esta preocupación por la expresividad en sus figuras imaginadas. Son netamente espańolas por su carácter y su perfil, y pertenecen a un artista profundamente imbuido del alma de su raza. Sólo en esta región la obra de Beltrán roza la de Zuloaga. Ambos celebran la belleza hispánica ardiente, grave, caprichosa, sensual, tal y como la pintó Goya" (Camille Mauclair, "L'art de Federico Beltrán Massés", en L'oeuvre de Federico Beltrán-Massés, París, Éditions d'Art Vizzavona, 1921, pp. 5-6). Este pequeño catálogo resulta especialmente significativo debido a la relevancia pública de los dos autores que contribuyeron con sus textos a la valoración de Beltrán entre el público francés. El escritor Camille Mauclair fue un firme defensor del esteticismo pictórico y de la obra de destacados pintores y escritores pertenecientes a la órbita estética del Simbolismo. El otro colaborador en esta publicación, Louis Vauxcelles, fue uno de los críticos de arte más influyentes de la belle époque, como lo demuestra el hecho de que los nombres de dos de los principales movimientos de las Vanguardias, el fauvismo y el cubismo, fuesen formulados por él por primera vez. 
delaire et de Rops, elles attirent, elles hantent, elles font peur, elles sont à la fois luxurieuses et ascétiques, et rendues plus terribles et plus voluptueuses encore par des éclairages de féerie, d'incendie ou de tempête ${ }^{11}$.

Baudelaire, Rops, Poe o Goya son nombres que, con frecuencia, afloran en este tipo de reflexiones a propósito de la obra de Beltrán. La belleza española, que el cubano había ubicado anteriormente en figuras tan características como la de la gitana, se plasmará, a raíz del escándalo provocado por La maja marquesa, en numerosas representaciones de este peculiar arquetipo castizo. Así lo afirma la abogada y escritora socialista Concha Peña en un artículo publicado en 1929:

Pero donde el pintor alcanza su más alta inspiración es en la interpretación de sus majas. Tienen estas mujeres de Beltrán un marcado carácter de perversidad, algo de ardiente, de enigmático, de terrible, que produce en el observador una rara emoción de incertidumbre lejana de tiempo y de espacio ${ }^{12}$.

Por otro lado, quizás como una muestra de desengaño o de definitiva rebeldía ante el gusto académico que había marginado su pintura en 1915, las majas que pueblan la pintura de Massés a partir de esa fecha han abandonado la luminosa sensualidad y el tenue cromatismo rococó de $L a$ maja marquesa. En lugar de mujeres entregadas a plácidos gozos terrenales, las majas de Massés se convierten, como apuntábamos, en temibles féminas de oscuras inclinaciones y perniciosos efectos sobre la voluntad masculina. Esta evolución queda de manifiesto en un comentario de José Francés acerca de una de las figuras que protagonizan un lienzo de la época, el espléndido Retrato de Mlle. Simone Bastat. Junto a la retratada, una

11 "Sus bellezas de cabelleras de tinieblas, rostros pálidos, bocas sangrientas, enormes ojos fosforescentes, cuerpos musculados y ágiles propios de felinos humanos, aparecen ante nosotros como hijas de Baudelaire y Rops. Ellas atraen, obsesionan, asustan, son a la vez lujuriosas y ascéticas, y resultan aún más terribles y voluptuosas inmersas en una iluminación de magia, de incendio o de tempestad" (Camille Mauclair, $o p$. cit., p. 6).

12 Concha Peña, "Las majas de Federico Beltrán", Alrededor del Mundo, 1586 (9 de noviembre de 1929), pp. 1251-1252. 
tenebrosa maja sugiere una nueva interpretación:

Es la maja de los cuadros de ayer, pero está cubierta de sombra y de tristeza. Ni la mantilla blanca, ni el traje de rutilancias audaces, ni la endiablada sonrisa de calenturientos carmines. Le cae de la cabeza al cuerpo, desmayadamente, una blonda negra. Le niebla el rostro la melancolía, y tiende con sus manos, amigas antes de los crótalos mońudos de colores, de las velas rizadas, de los claveles púrpura, un cofrecillo de joyas a Mlle. Simone Bastat ${ }^{13}$.

Adornada ya con rasgos de innegable fatalidad, como venimos diciendo, fueron varias las versiones de este mismo motivo que Beltrán incluyó en retratos, alegorías y pinturas de temática costumbrista o literaria. El mencionado artículo de José Francés formaba parte de un catálogo editado en 1923 que contiene ya un conjunto nada despreciable de "majas" entre las obras incluidas. Además de en el ya citado Retrato de Mlle. Simone Bastat, encontramos mujeres de este tipo en obras como El juicio de Paris, el Retrato de Irene Narezo de Beltrán o La maja de luto.

\section{LA SÍNTESIS ICONOGRÁFICA: LA MAJA MALDITA (I9I8)}

La más conocida de las majas de Beltrán es, sin embargo, La maja maldita, nuestro objeto de estudio en este artículo. Sabemos que Beltrán la pintó en 1918 y que fue expuesta en París en el marco de la primera exposición que Beltrán celebró en la capital francesa tras instalarse allí. Según otro artículo de Camille Mauclair, La maja maldita fue uno de los lienzos más admirados por los parisinos, y su carácter excepcional favoreció que el pintor español tuviese la oportunidad de exponer sus obras

13 La labor que José Francés desempeñó como crítico de arte en publicaciones de amplia distribución ha sido el tema principal de la tesis doctoral de María Piedad Villalba Salvador, José Francés, crítico de arte, Madrid, Universidad Complutense, 2002. Asimismo, la influencia de Baudelaire en la obra de este escritor queda apuntada y analizada por Begoña Sáez Martínez en su imprescindible ensayo Las sombras del modernismo. Una aproximación al decadentismo en España, Valencia, Institució Alfons el Magnànim, 2004, p. 313. 
en la Exposición Universal de Venecia en $1921^{14}$. Se trata, en todo caso, de un magnífico lienzo, una pintura dotada de un aspecto enigmático y seductor que fusiona sabiamente distintas tradiciones iconográficas y que, al mismo tiempo, condensa a la perfección los rasgos de fatalidad tan apreciados por los artistas finiseculares. [Fig. 2]

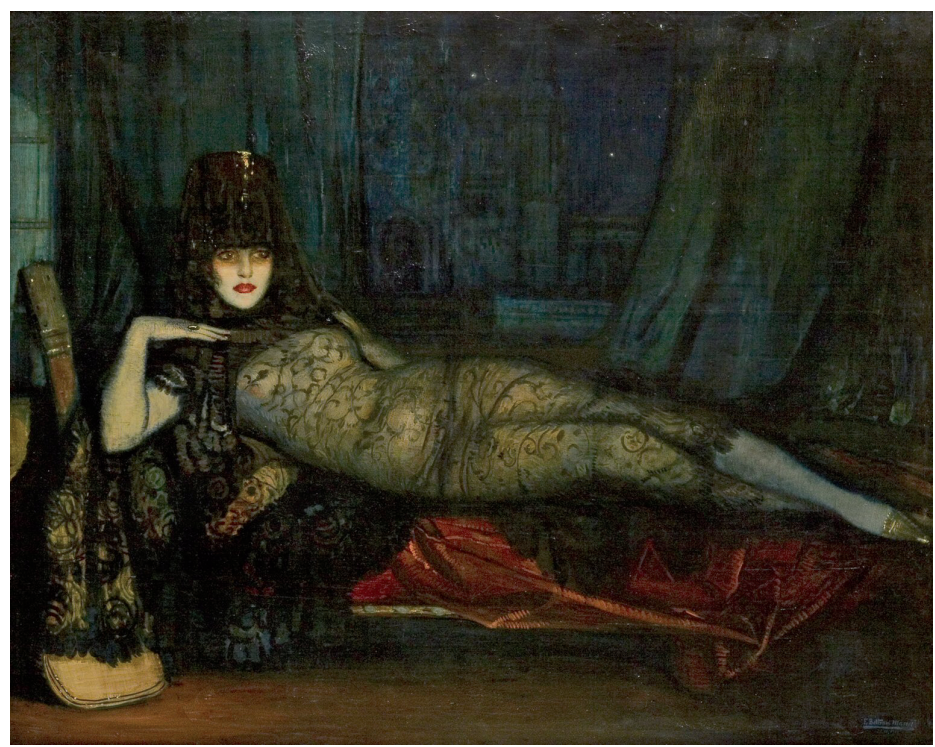

Fig. 2.

El contenido general de esta obra lo proporciona la siguiente descripción de Concha Peña:

Teatralmente tendida sobre unos rasos obscuros, una mujer morena, hermosísima, se envuelve en una mantilla de blonda transparente, tocada con ancha peineta, en forma de tiara, que le da un aspecto hierático de ídolo embrujado. Por la ventana abierta hacia la noche, serena y estival, se ve lejana la esbelta silueta de una gótica catedral... ${ }^{15}$

14 Camille Mauclair, "Le peintre espagnol F. Beltran-Masses", Le Gaulois Artistique (25-6-1929), pp. 337-337.

15 Concha Peña, op. cit., p. 1252. 
A la hora de plantear un tema similar - una maja tendida- no cabe duda de que el primer modelo que pudo tener en cuenta Beltrán Massés fue el propuesto por Goya en sus célebres La maja desnuda, pintada entre 1790 y 1800, y La maja vestida, variación de la anterior, datada entre 1802 y 1805. Ambas obras disfrutaban de una enorme popularidad a principios del siglo XX y, de hecho, la referencia a estas pinturas ya surgió con motivo del escándalo suscitado por La maja marquesa (1915), cuando algunas voces críticas caracterizaron a la mujer retratada por Beltrán como "descendiente de la de Alba"16. Sin embargo, la presencia de las majas en la pintura espańola del siglo XIX no es en absoluto anecdótica, ya que el imaginario romántico dedicó no poca atención a la representación de mujeres vestidas de forma popular en distintas actitudes. Este casticismo decimonónico, escasamente estudiado y hoy felizmente rescatado por algunas monografías y exposiciones, dejó obras tan interesantes como las firmadas por José María Domínguez Bécquer, recientemente recuperadas ${ }^{17}$ y que constituyen, a juicio del mayor conocedor de su obra, "una de las muestras mejores y más completas" del discurso casticista ${ }^{18}$. Tampoco era un motivo extraño en la pintura de principios del siglo XX. Los contemporáneos de Federico Beltrán Massés firmarían óleos protagonizados por mujeres reclinadas y ataviadas de modo castizo, como las debidas al pincel de Manuel Benedito Vives (La Gavilana, 1910, y Gitana, 1909) ${ }^{19}$.

16 Gabriel García Maroto, "El reinado de la mediocridad", en Federico Beltrán y la Exposición Nacional de Bellas Artes de MCMXV, Madrid, Imprenta Espańola, 1915, p. 25.

17 Resulta imprescindible consultar la monografía de Jesús Rubio Jiménez, José María Dominguez Bécquer, Sevilla, Diputación de Sevilla, 2007. En su indagación acerca de la obra del padre de Valeriano y Gustavo Adolfo Bécquer, un importante pintor costumbrista del Romanticismo sevillano, Rubio Jiménez registra varias representaciones del tema de la maja, como la pintura Maja y Celestina (s. f., lámina 9) o la aguada Maja o Mujer con mantilla (1834), recogida a su vez en Manuel Piñanes García-Olías, "Algunas aguadas inéditas de José D. Bécquer”, Laboratorio de Arte, 6 (1993), pp. 359-366.

18 Jesús Rubio Jiménez, op. cit., p. 92.

19 A finales de 2014 la Fundación Bancaja de Valencia acogía una exposición titulada Herederas de las Majas de Goya. Pintura española del cambio de siglo XIX-XX. Planteaba, a través de un conjunto de importantes obras, la persistencia del modelo de la mujer reclinada en la pintura española finisecular. El catálogo de la misma (Isabel Justo, Herederas de las Majas de Goya. Pintura española del cambio de siglo XIX-XX, 
No obstante, la relajada sensualidad de las majas goyescas o el amable costumbrismo de las castizas majas decimonónicas distan mucho de la oscura sofisticación de La maja maldita. Tampoco el atuendo elegido por Beltrán resulta historicista en un sentido estricto, ya que sólo los pequeńos zapatos dorados de su maja coinciden con los que luce la protagonista de La maja vestida; en el resto de su figura, las vestimentas populares de la dama goyesca han sido sustituidos por una perturbadora indumentaria. En ella, la severidad religiosa de la peineta y la mantilla contrasta con la pálida desnudez entrevista a través de las blondas transparentes que cubren el resto de su cuerpo. La originalidad de este atavío queda de manifiesto en las palabras del crítico Luis Doreste, cuando menciona su particular modelado del desnudo femenino "que enciende el espíritu en un espíritu contemplativo inacabable, [...] vistiendo en blondas las desnudeces admirables, creación de singular encanto" ${ }^{20}$.

La transparencia de estos tejidos sugiere así la desnudez y la plena sensualidad de un cuerpo representado como objeto de deseo. Los tintes fúnebres de la escena y el propio título de la obra -La maja maldita, que reviste esta imagen de una cierta dimensión demoníaca- sitúan este deseo sexual bajo un velo fatídico, convirtiendo esta representación de sensualidad peligrosa en un símbolo de la fatalidad femenina tan cara a los artistas finiseculares. Louis Vauxcelles subraya este aspecto en una reflexión a propósito de las figuras femeninas de Beltrán:

Regardez ces filles à la chair capiteuse, tiède et ambrée, aux yeux de phosphore, aux seins fleuris meurtris de morsures, ces corps d'une souplesse féline, élastique, musclée, prêts aux contorsions paroxystes, aux déhanchements de l'étreinte et de la danse. Ce sont, dirons les enthousiastes, des fleurs vénéneuses, des fruits maudits ${ }^{21}$.

Valencia, Fundación Bancaja, 2014) incluye un interesante texto de la comisaria de la muestra y analiza la evolución de este motivo pictórico con especial atención a sus características sociales e interartísticas.

20 Luis Doreste, “Crónicas parisienses: Una visita a Federico Beltrán”, Cosmópolis, 12 (1921), p. 551.

21 "Mirad a estas muchachas de carne embriagadora, tibia y ambarina, de ojos de fósforo, senos floridos lacerados por mordeduras; estos cuerpos de elasticidad felina, flexible, musculosa, aptos para las contorsiones paroxistas, para las contorsiones del amor y de la danza. Sus admiradores las llamamos flores venenosas, frutos malditos" 
La fusión modernista entre amor y muerte queda de manifiesto en este fragmento, que contiene muchos de los tópicos del erotismo finisecular. Vauxcelles menciona la "carne embriagadora, tibia y ambarina", un atributo que caracteriza la sensualidad como una perturbadora emanación. A su vez, las referencias al cuerpo "felino", dado a las "contorsiones", al "paroxismo" y a las "dislocaciones de la danza", remiten inevitablemente a la figura de la bailarina que tiene en Salomé su más egregia precursora y que, en la época, se había popularizado enormemente a través de numerosos espectáculos de danzarinas exóticas. Del mismo modo, otro de los elementos que llaman la atención de los críticos es la mirada de esta figura trágica. La maja maldita no ostenta un semblante relajado y luminoso, como la maja goyesca, ni la indiferencia de la Olympia de Manet:

Mira fijamente hacia una remota ilusión que no llega, y hay en sus ojos felinos y misteriosos un fondo de refinada sugestión que ofrecen la ventura de amores fatales, paraísos deleitosos, vibrando la mueca de un deseo desconocido en su boca sangrienta de labios gordezuelos y sensuales. Resumida en esta concepción suprema, exquisitamente interpretada, hay unas suaves tonalidades de misticismo pagano, que contrasta con un espíritu voluptuoso que se manifiesta en el misterio de sus ojos rasgados, donde se lee el más ferviente y realista deseo de vivir $^{22}$.

Para otros autores, este carácter trágico desemboca inevitablemente en la figura de la femme fatale, que también adoptaba una actitud de enigmático hieratismo en la obra de pintores como Gustave Moreau. Tal es el caso de Camille Gronkowski, crítico y conservador del Musée du Petit Palais -el primer espacio parisino donde Beltrán expuso una selección de sus obras- que, en un artículo dedicado a la pintura española contemporánea, no duda en atribuir a esta obra una serie de rasgos que la emparentan con dos autores literarios fundamentales en el imaginario de la generación simbolista: Baudelaire y Samain.

(Louis Vauxcelles, "Beltran et la peinture espagnole contemporaine", en L'oeuvre de Federico Beltrán-Massés, s. p.).

22 Concha Peña, op. cit., p. 1252. 
Mais la Maja n'est pas seulement une perle de nacre sertie de sombres pierreries: par l'arabesque onduleuse, par le geste hiératique, et surtout par l'expression tendue et ardente du regard, cette féline créature symbolise la Luxure, celle que chanta Baudelaire, et surtout Albert Samain, dans les strophes fameuses qui nous viennent invinciblement à la memoire ${ }^{23}$.

En este fragmento no sólo resulta llamativo el delicado lirismo parnasiano que impregna imágenes como "perla de nácar extraída de sombrías pedrerías" para describir el efecto de la piel pálida bajo las oscuras blondas transparentes y el brillo cadavérico de la tez de la mujer representada, sin duda el punto más luminoso del cuadro; también resulta interesante la recurrencia del término "felino" a la hora de caracterizar las representaciones femeninas de Beltrán: sinuosas, elegantes y enigmáticas. Más allá de la serpentina silueta de la figura que protagoniza el cuadro, el resto de elementos que forman parte de la composición presenta un indudable interés, debido a su particular reinterpretación de ciertas tradiciones iconográficas asociadas a la representación de la belleza femenina. La escena se desarrolla en un entorno nocturno, apenas revelado entre las sombras, pero repleto de elementos plenamente significativos, justificando la apreciación que apuntaba Camille Mauclair en uno de sus ensayos sobre la obra de Massés: "Il lui est impossible de présenter un portrait sans le relier à un décor qui est "une projection d'âme» autour de la figure charnelle dont il restitue la ressemblance et scrute l'expression" ${ }^{24}$.

La maja se encuentra tendida sobre un diván o cama cubierta de lujosos ropajes de color rojizo. Tras ella, unas cortinas dejan ver la "esbelta

23 "Sin embargo, la Maja no es sólo una perla de nácar engastada en oscuras pedrerías; por el arabesco ondulado, por el gesto hierático, y sobre todo por la expresión tensa y ardiente de su mirada, esta criatura felina es un símbolo de la Lujuria, la que cantó Baudelaire y, sobre todo, Albert Samain, en las famosas estrofas que nos vienen invencibles a la memoria" (Camille Gronkowski, "L'Évolution de la Peinture Espagnole Moderne", La Reinaissance de l'Art Français et des Industries de Luxe, mayo de 1919, p. 22).

24 "Le resulta imposible presentar un retrato sin vincularlo a un decorado que sea una proyección del alma en torno a la figura carnal cuyo parecido restituye y cuya expresión escruta" (Camille Mauclair, op. cit., p. 5). 
silueta de una catedral gótica" que mencionaba Concha Peña en su descripción. Parte del escenario está envuelto en la oscuridad, pero parece claro que en este punto la obra de Beltrán se aparta definitivamente de la influencia goyesca -recordemos que las dos Majas se encuentran aisladas, rodeadas por un espacio indeterminado y vacío- y se aproxima a otra fuente iconográfica muy distinta: la de las representaciones de Venus en la pintura del Renacimiento veneciano. En ese sentido, es el nombre de Tiziano el más fácilmente identificable con este sistema de representación. Si tomamos como ejemplo el óleo Venus y el tañedor de laúd (1560, hoy conservado en el Metropolitan Museum de Nueva York), las similitudes con el décor de la pintura de Beltrán resultan claramente visibles. Así, los suntuosos paños purpúreos del lecho y los pesados cortinajes que dan paso a un paisaje existente más allá de los límites de la estancia son recursos propios de la pintura veneciana que Beltrán reinventa aquí con un exquisito barniz decadentista. La figura masculina está ausente, pero, por otro lado, el laúd que ameniza la estancia de Venus en la obra de Tiziano ha sido aquí sustituido por una guitarra espańola situada junto al cabecero de la cama. Se trata, sin duda, de otro guińo al casticismo español tan apreciado por Beltrán, posiblemente interesado por el mundo plástico del flamenco que tan fructífero había resultado en la obra de Julio Romero de Torres.

Por otro lado, al igual que los pintores venecianos, Beltrán gozaba de una merecida fama como exquisito colorista, y dicha maestría queda sobradamente demostrada en esta pintura. Todo este decorado se encuentra invadido por un cromatismo oscuro, delicado y evocador, lleno de sutiles contrastes y heredero directo de la pintura simbolista. A excepción de la suave iluminación dorada que recorre la figura central y que parece proceder de un candil invisible, la escena es nítidamente nocturna, lo que la distancia también de las luminosas representaciones de Tiziano. El rasgo más característico es, sin duda, el color azulado -índigo o cobalto- que domina todo el fondo de la pintura, combinándose tenuemente con el negro y el verde. Dicho registro cromático, "que aparece en sus telas con una prodigalidad excesiva" 25 , es el rasgo más inmediatamente reconocible

25 María Victória Salom Vidal, "Notas de color", en Federico Beltrán Massés. Castizo cosmopolita, ed. Joan Abelló, Madrid/Barcelona, Real Academia de Bellas Artes de San Fernando/Reial Cercle Artístic de Barcelona, 2012, pp. 160-163 (p. 163). 
de gran parte de la obra pictórica de Beltrán, y como tal fue subrayado por los expertos:

Le triple envoi de Federico Beltran attire notre attention: c'est un moderne et c'est un symboliste; comme Anglada, il aime de jouer avec les couleurs rares, et vous admirerez les profonds cobalt de la nuit étoilée, derrière le corps pâle de la Maja maudite, en étrange harmonie avec les verts foncés de la draperie ${ }^{26}$.

En términos similares se expresaba Louis Vauxcelles, subrayando el poder lírico de dicha maestría en el empleo del cromatismo, y haciendo énfasis en la capacidad evocadora del fondo, lleno de formas apenas esbozadas que remiten a la España remota, oriental, musical y arcaica que había cautivado a los románticos europeos:

L'harmonie dominante est l'indigo: bercement des nuits enchantées, des jardins endormis sous la lune, chansons de Granados chuchotées mezzo voce, corps de femmes pâmés, extasiés, s’allongeant, s'étirant, langoureux, d'un poids, d'une densité volumineuse, ces filles se drapent au creux de mantilles polychromes ${ }^{27}$.

A ojos de sus contemporáneos, esta fuerza visual justificaba plenamente la valía artística de la obra, relegando a un segundo plano las posibles connotaciones morales que sólo parecían interesar a una élite academicista definida invariablemente como "mediocre" por todos aquellos que se consideraban víctimas de su tradicionalismo y sus prejuicios estéticos. De hecho, no resulta inesperado encontrar, en la valoración de la pintu-

26 "La triple apuesta de Federico Beltrán atrae nuestra atención; es un moderno y es un simbolista; como Anglada, le gusta jugar con los colores raros, y sin duda admiraréis el profundo cobalto de la noche estrellada tras el cuerpo pálido de la Maja Maldita, en extraña armonía con los verdes oscuros de los drapeados" (Camille Gronkowski, op. cit., p. 22).

27 "La armonía dominante es el índigo, que nos mece igual que lo hacen las noches encantadas, los jardines adormecidos bajo la luna, las canciones de Granados susurradas a media voz, los cuerpos femeninos que desfallecen, extasiados, que se alargan, se estiran, lánguidos, con un peso y una densidad voluminosa, de chicas que se envuelven en polícromas mantillas" (Louis Vauxcelles, "Beltran et la peinture espagnole contemporaine"). 
ra de Beltrán, juicios que recuerdan inevitablemente a los principios del Movimiento Estético británico, defendiendo la búsqueda de cualidades y emociones puramente plásticas, despojadas de toda intencionalidad social o moral.

Je ne crois pas pourtant que le peintre qui les a créées ait songé à les considérer autrement que comme de passionnants motifs d'harmonie chromatiques, des prétextes à des noirs, à des rouges, à des verts prasins, à certains tons de perle et de saphir que je n'ai vu qu'à lui depuis le Tintoret ${ }^{28}$.

En las alusiones a estos tonos y armonías cromáticas resuenan inevitablemente ecos de aquellos pintores que, como Whistler, habían sentado un precedente a la hora de dar prioridad, en su actividad artística, al ámbito formal y plástico sobre el temático, persiguiendo únicamente experiencias sensoriales y espirituales derivadas de la contemplación de la forma y el color como entidades abstractas. En ese sentido, al despojar a sus representaciones de todo realismo cromático y apostar por una iluminación dramática y casi onírica, Beltrán Massés adopta una postura de plena modernidad, en la que el cuadro funciona como una creación visualmente autónoma que no necesita referentes externos para justificarse. Por otro lado, esta creación de un mundo plásticamente independiente se ve reforzada por un carácter literario que sus contemporáneos no dudaron en subrayar. Nuevamente es Camille Mauclair quien favorece esta interpretación gracias al siguiente fragmento en el que reflexiona acerca de la naturaleza poética del universo pictórico de Beltrán: "Il y a là une opération de l'esprit, une transposition de la poésie à la peinture, qui s'accomplit dans tous les tableaux où Beltran présente des têtes d'expression. Il y reste peintre, mais il y est pleinement poète" 29 .

28 "No creo, sin embargo, que el pintor que las ha creado las considere algo más que apasionantes motivos de armonía cromática, pretextos para pintar negros, rojos, verdes y ciertos tonos de perla y de zafiro que no he visto en nadie más desde Tintoretto" (Camille Mauclair, "L'art de Federico Beltrán Massés", en L'oeuvre de Federico Beltrán-Massés, p. 6).

29 "Hay ahí una operación del espíritu, una trasposición de la poesía a la pintura que se cumple en todos los cuadros en los que Beltrán demuestra que, sin dejar de ser pintor, es plenamente poeta" (Camille Mauclair, op. cit., p. 6). 
Volviendo al cuadro, hoy sabemos que la modelo no era una mujer anónima, sino la bailarina Tórtola Valencia, uno de los personajes más célebres de la España de principios del siglo XX. Bailarina exótica, fue la introductora en Espańa de nuevas modalidades de danza que combinaban las técnicas más clásicas con inspiraciones revolucionarias: animales, abstractas y étnicas. También ocupó una posición de indudable importancia en los círculos más avanzados -y escandalosos- de la alta sociedad madrileña. El escritor y periodista César González Ruano recordaba haberla conocido en casa de Antonio de Hoyos y Vinent, donde la vio bailar "con tanto arte como poca ropa, y me quedé fascinado. Era encantadora y absurda, como un ídolo falso" ${ }^{30}$. En otro fragmento, el mismo autor la ubica en la controvertida pandilla del autor de $A$ flor de piel:

[Hoyos y Vinent] me enseñó los bailes de máscaras de barrios bajos verdaderamente increíbles, los últimos cafés de cante que quedaban, como el de la Encomienda, que se conservaba lo mismo que los del siglo pasado, como una estampa puesta de espaldas a nuestra época, y en su casa conocí a Tórtola Valencia, al pintor Federico Beltrán Massés, a Julio Antonio el escultor, [...] a Pepito Zamora, a Gloria Laguna y al extrañísimo marqués de Villalobar, que era otro monstruo de los buenos $^{31}$.

Entre los hallazgos de Tórtola Valencia estuvo la reivindicación en clave vanguardista del folclore español: suya fue, por ejemplo, la innovación de emplear la mantilla y la peineta tradicionales como atuendo artístico sobre el escenario, desprovisto de su carácter religioso. Dentro de su repertorio, que incluía motivos orientalistas como Salomé (y así la retrató Rafael de Penagos en un célebre cartel para el Baile del Círculo de Bellas Artes), también estaba el de la maja goyesca. De hecho, en esta misma época firmaría un contrato publicitario con la casa cosmética Myrurgia para ser la imagen de una línea de productos llamada significativamente "Maja" ${ }^{2}$. Y como maja posó ante Beltrán Massés, convirtiéndose en

30 César González Ruano, Memorias: mi medio siglo se confiesa a medias, Sevilla, Renacimiento, 2004, p. 229.

31 César González Ruano, op. cit., p. 86.

32 Las ilustraciones publicitarias y el diseño de los envases de la firma Myrurgia reflejan la extraordinaria creatividad art déco de inicios del siglo XX, tal y como demuestra 
la primera de una larga serie de celebridades internacionales a quienes retrataría, y que con los ańos incluiría nombres como Anita Delgado, la Maharaní de Kapurtala, actrices de Hollywood como Joan Crawford o Greta Garbo y estrellas internacionales como el actor de cine mudo Rodolfo Valentino, con quien Beltrán llegó a convivir durante su estancia estadounidense.

Que la modelo de La maja maldita sea Tórtola Valencia no implica que nos hallemos ante un retrato sensu stricto. Sus rasgos están estereotipados y rozan la androginia. Sin embargo, su magnetismo era innegable, y quizás eso explique que, al ver esta pintura, la conocida Marquesa Casati, amante de D’Annunzio y alma viviente de la Venecia más rutilante de la belle époque, encargara un retrato al espańol con una atmósfera similar. El Retrato de la Marquesa Casati (1920) está desprovisto de los elementos casticistas que decoraban el de Tórtola Valencia, pero comparte un idéntico registro cromático y un aire espectral subrayado por la rigidez y palidez de su protagonista, que en esta ocasión sostiene, como la calavera hamletiana, una esfera de cristal azul que le había regalado Gabriele d'Annunzio y que ella consideraba su posesión más preciada.

Todo lo anterior justifica que un autor de intereses cercanos al Simbolismo, como era el joven Armand Godoy, se sintiera inmediatamente atraído por La maja maldita, que bien pudo ver en París en 1919, año de la primera exposición de Beltrán en la capital francesa. También es posible que la contemplara posteriormente, estimulado muy posiblemente por los elogios de voces tan autorizadas y prestigiosas como Camille Mauclair y Louis Vauxcelles. En todo caso, parece obvio que un joven literato entregado a la causa del Modernismo se sintiera inmediatamente seducido ante la contemplación de esta imagen y decidiera proponer un texto poético correlativo, destinado a ser difundido de manera conjunta con una reproducción de la obra plástica que la había motivado.

una original exposición celebrada en 2003 en el Museu Nacional de Catalunya y su correspondiente catálogo: Myrurgia 1916-1936. Belleza y glamour, Barcelona, Lunwerg Editores, 2003. 


\section{La tRANSPOSITION D'ART DE Armand Godoy}

La crítica ha considerado los inicios de la carrera literaria de Armand Godoy (La Habana, 1880-París, 1964) como un mero prólogo a su personalidad literaria posterior, definitivamente orientada hacia el catolicismo. Sin embargo, no cabe duda de que dichos inicios, asociados a las formas y los temas del Simbolismo tardío, presentan un interés considerable. Esto no se debe únicamente a su particular cosmopolitismo -aunque nacido en Cuba, Armand Godoy desarrolló la mayor parte de su obra literaria en francés-, sino también a su interés por la relación entre la literatura y las artes visuales. No resulta extraño que así fuera, dadas sus influencias literarias. Entre ellas destacaban las de Baudelaire -al que dedicó un importante estudio ${ }^{33}$-, pero también José María de Heredia -al que ofrendó su primer poemario, en 1925, Á José-Maria de Heredia, sonnets ${ }^{34}$-. El nombre del poeta parnasiano posiblemente planeara sobre su escritorio cuando, en 1926, dio a las prensas un opúsculo titulado significativamente Tryptique ${ }^{35}$. En esta obra, lujosamente editada, tres sonetos inspirados en tres obras de Beltrán Massés se hallaban enfrentados a las reproducciones en fototipia de las tres pinturas citadas ${ }^{36}$. Procedemos a reproducir el titulado La maja maudite, pues corresponde a la pintura de Beltrán Massés que ya hemos analizado.

\section{LA MAJA MAUDITE}

Derrière ton regard séraphins et démons tissent la maille fine aux subtils tentacules où se tordent les coeurs, pitieux et ridicules,

33 Armand Godoy, La bonté de Charles Baudelaire, Montreux, Imp. Ganguin \& Laubscher, 1942.

34 Armand Godoy, À José-Maria de Heredia, sonnets, París, Lemerre, 1925.

35 El título completo es Tryptique. La Maja Maudite. Salomé. Vers les étoiles. Trois poèmes d'Armand Godoy. Illustrée de trois tableaux de D. Beltran Masses. Préface de Camille Mauclair en fac-similé, París, Impr. Daniel Jacomet, 1926.

36 Una primera aproximación a este diálogo interartístico entre Armand Godoy y Federico Beltrán Massés a propósito del soneto que el hispano dedicó a Salomé se encuentra en el artículo de Jesús Ponce Cárdenas y Carlos Primo Cano, "Armand Godoy o la écfrasis decadente”, AnMal Electrónica 32 (2012), pp. 133-153. 
pendant que l'orgue chante et grondent les sermons.

Sur ton corps de Vénus quelques noirs goëmons dessinent des serpents crispés et minuscules, et dans ta bouche en feu les sanglants crepuscules reprennent le refrain maudit: "Mourons, aimons!"

Au bout de cette main droite comme une flèche tes ongles sont au guet. Quelle blessure fraîche vont-ils border d'un rouge et sinistre ostensoir?

Mais la guitare est lá que ta mantille voile: pour se détendre ils font sangloter chaque soir son coeur sonore épris d'une invisible étoile ${ }^{37}$.

Si, como se ha señalado, el soneto dedicado a Salomé abandonaba la descripción del lienzo para adentrarse en la recreación de elementos iconográficos asociados a Oscar Wilde y a Beardsley ${ }^{38}$, el segundo poema del tríptico, titulado La maja maldita, sí se ciñe a los elementos que aparecen en la obra pictórica de Beltrán Massés. Hemos comentado ya cómo en la recreación del pintor espańol se producía una peculiar revisión de dos figuras arquetípicas (las Venus renacentistas y las majas goyescas); para Godoy, a estas dos referencias hay que añadir una tercera: la de la religiosidad popular espańola, que era uno de los atributos indisociables del casticismo esotérico de las primeras décadas del siglo XX. También resulta algo muy llamativo en un autor como Godoy que, cuando trató temáticas religiosas, lo hizo desde la devoción y la espiritualidad.

Aquí, la atmósfera es muy distinta. Si hay devoción, es claramente perversa. El poder de seducción de la maja maldita combina elementos angelicales y satánicos, esos "serafines y demonios” que convierten su mirada en una red que apresa a "corazones piadosos y ridículos". La figura que

37 "Tras tu mirada serafines y demonios / tejen la fina malla de sutiles tentáculos / en que se retuercen los corazones, piadosos y ridículos, / mientras el órgano canta y rugen los sermones. // Sobre tu cuerpo de Venus negras algas / dibujan serpientes crispadas y minúsculas / y en tu boca encendida los sangrientos crepúsculos / repiten el estribillo maldito: “Muramos, amemos!”. // Al cabo de esta mano recta como una flecha / tus uñas acechan. ¿Qué herida reciente / van a ribetear con una roja y siniestra custodia? // Pero la guitarra está ahí, velada por tu mantilla: / cada noche, para relajarse, extraen un sollozo / de su corazón sonoro, tomado por una invisible estrella”.

38 Jesús Ponce Cárdenas y Carlos Primo Cano, op. cit., pp. 128-129. 
evoca Godoy es, por tanto, una femme fatale en su versión más abiertamente demoníaca; especialmente porque la escena de la seducción no se produce en un elegante diván, sino en un templo religioso: así lo deja adivinar el verso cuarto, que narra cómo la seducción tiene lugar "mientras el órgano canta y rugen los sermones". Estamos, por lo tanto, en una iglesia española. En una catedral incluso.

Serafines, demonios, música sacra y catedrales; los elementos religiosos no acaban aquí: en el primer terceto, el poeta, que se dirige a la maja en segunda persona, compara la herida que provocan sus uńas afiladas con "una roja y siniestra custodia". También podríamos ubicar dentro de la imaginería religiosa el propio atuendo de la protagonista: vestida únicamente con una mantilla negra de origen devoto que, al cubrir apenas su pálida desnudez, se carga de connotaciones eróticas y mórbidas.

Nos hallamos, pues, ante un décor clásico de la imaginación romántica e incluso gótica. No en vano uno de los ejemplos más conocidos de femme fatale se encuentra en El Monje, de Mathew Lewis, una historia de seducción demoníaca ambientada en un convento madrileño. La historia, sobradamente conocida, se centra en las tentaciones que experimenta un fraile con fama de santo, Ambrosio, ante la seducción de Matilde, que ha ingresado en el monasterio haciéndose pasar por hombre. Uno de los episodios críticos de la novela tenía lugar cuando Ambrosio descubre la naturaleza femenina y tentadora de Matilde y afirma que "the moonbeams darting full upon it enabled the monk to observe its dazzling whiteness" 39 . La palidez del cuerpo desnudo de La maja maldita es, ese sentido, la misma palidez de Matilde en la sobriedad del monasterio, que también es la de las espectrales heroínas bíblicas de Gustave Moreau o de la Salomé de Wilde.

Volvamos, sin embargo, al velo de encaje que la recubre en el cuadro de Massés, y que Godoy describe como "negras algas que dibujan serpientes crispadas y minúsculas”. En la imagen oceánica de las algas resuena la lejana voz de las sirenas; a su vez, las serpientes son una muestra de la iconografía más clásica de la fatalidad femenina, cuyo recorrido cuenta con ejemplos tan ilustres como los cabellos ofidios de la Medusa, la presencia

39 "La luz de la luna caía de lleno sobre el seno de Matilde, y permitía que el monje lo contemplara en su cegadora blancura" (Matthew Gregory Lewis, The Monk: A Romance. In Three Volumes, Londres, J. Saunders, 1796, p. 127). 
demoníaca que tienta a la Eva del Génesis -la Lilith mesopotámica- o, también, las representaciones literarias y pictóricas de Cleopatra. Con estas referencias en mente, Godoy elimina el origen devocional de la prenda y el encaje de la mantilla aparece transmutado aquí en un atuendo diabólico que simboliza el mortífero poder de seducción de la femme fatale.

En esta blancura espectral ribeteada de amenazadoras formas negras se engarza el color rojo de los labios: Godoy la describe como una boca encendida -en llamas- que evoca sangrientos crepúsculos. Por un lado, los ecos de Wilde son obvios; no en vano el primer soneto del tríptico que analizamos, el dedicado a Salomé, se abría con una cita de Wilde enormemente ilustrativa -"No hay nada más rojo que tu boca"-. Por otro lado, conviene apuntar que, aunque no se apreciara en la fototipia incluida en este opúsculo, el original de Beltrán Massés destacaba por el rojo intenso de los labios de la protagonista. De hecho, se conserva una reproducción de dicha pintura en la que la modelo de la misma, Tórtola Valencia, escribió una dedicatoria al pintor aludiendo a "Le tableau qui inventa les lèvres rouges en 1918 au Petit Palais". En la misma línea cromática, el rojo sangriento, se inserta la evocación del poder lacerante de las uńas de la maja: el poeta, inspirado por su rectitud y su aspecto afilado, lamenta (o alaba) su capacidad para herir y provocar en la piel de su víctima "una roja y siniestra custodia”.

Concluye el poema, en el segundo terceto, con una alusión a la guitarra. Recordemos lo que mencionaba, a propósito de este motivo, el catedrático Pérez Rojas:

Todos los elementos configuradores de la iconografía contaminada de flamenquismo confluyen en ella: la guitarra, la peineta, la mantilla... pero orquestado de un modo muy personal en el que la maja se erige en prototipo de moderna vamp. La mantilla negra de blonda subraya la voluptuosa desnudez, tenuemente velada, de la imagen femenina, dotando a su cuerpo de un mayor poder de atracción al jugar con la imagen ambigua de vestida y desvestida. La mantilla cubre el cuerpo de la mujer y también de la guitarra con sus redondeadas formas femeninas ${ }^{40}$.

40 Francisco Javier Pérez Rojas, "Federico Beltrán Massés, un art déco hispano con vocación cosmopolita", en Federico Beltrán Massés. Castizo cosmopolita, pp. 137-149 (p. 144). 
La guitarra, por lo tanto, puede leerse una extensión del cuerpo de la modelo en el plano simbólico de la pintura. También en el del poema, ya que el instrumento musical podría ser un fetiche que sustituye al cuerpo masculino - rasgado por las uńas, etc.-. Por otro lado, no se le escapan a Godoy las resonancias mitológicas que impregnan la imagen más allá de su evidente carga casticista; en el quinto endecasílabo menciona su "cuerpo de Venus", lo que alude tal vez a la iconografía que ya mencionábamos, y que, más allá de la evidente referencia goyesca, vincula esta pintura con las Venus venecianas del siglo XVI.

Las referencias, como vemos, son múltiples, y demuestran la variedad de juicios e interpretaciones que esta obra de Beltrán suscitó en sus contemporáneos. Si Armand Godoy conocía la identidad de la modelo, Tórtola Valencia, la omitió. En cualquier caso, su mirada estaba puesta más allá, y optó por una ensońación casticista donde resuenan ecos de Baudelaire, Goya y la pintura clásica, y donde las posibilidades interpretativas de la pintura quedan supeditadas a un único impulso: una fascinación erótica hacia la femme fatale a la que, como hemos visto, tampoco fueron ajenos sus contemporáneos. Por ello, las obras de Godoy y Beltrán Massés muestran que, a pesar de su desvanecimiento progresivo, aún era posible encontrar, en la Europa de las Vanguardias, rescoldos de una de las figuras más características de la iconografía finisecular; aquella belle dame sans merci que, un siglo después de haber sido bautizada por John Keats, seguía siendo considerada como un símbolo enormemente poderoso de las luminosas profundidades del deseo. 